\title{
Multimodal Imaging Characteristics and Presumed Cause of Intrapapillary Hemorrhage with Adjacent Peripapillary Subretinal Hemorrhage
}

\author{
Xian Zhang $\mathbb{D}^{*}$ \\ Xi Cheng $\mathbb{D}^{*}$ \\ Bo Chen \\ Xufang Sun
}

Department of Ophthalmology, Tongji Hospital, Tongji Medical College, Huazhong University of Science and Technology, Wuhan, People's Republic of China

*These authors contributed equally to this work
Correspondence: Bo Chen; Xufang Sun Department of Ophthalmology, Tongji Hospital, Tongji Medical College, Huazhong University of Science and Technology, 1095 jiefang Ave., Wuhan, 430030, People's Republic of China Tel +8683663410

Email eyechen@aliyun.co; sunxufang2016@I63.com
Purpose: To describe the multimodal imaging findings of intrapapillary hemorrhage with adjacent peripapillary subretinal hemorrhage (IHAPSH) and reveal the possible mechanism of this rare benign disease.

Patients and Methods: Observational study. Three eyes in three patients with intrapapillary hemorrhage with adjacent peripapillary subretinal hemorrhage were evaluated at the retina division of our institution. We describe the multimodal imaging findings including visual field examination, fundus photography, fluorescein and indocyanine green angiography (FFA\&ICGA), spectral-domain optical coherence tomography (OCT), and ultrasonography.

Results: Three myopic patients with IHAPSH shared a similar clinical course and multimodal imaging appearance. The symptom was sudden dark shadows floating in the affected eye with mild visual blurring. Fundus photography showed hemorrhage in intrapapillary and subretinal, as well as optic disc bulges on the nasal side with local vitreoretinal separation in the affected eyes. OCT confirmed intrapapillary and subretinal hemorrhage with obviously elevated optic papilla in the affected eye and local vitreoretinal separation at the temporal side of optic disc together with vitreoretinal adhesion at the superonasal edge. FFA\&ICGA ruled out optic drusen and neovascularization. B-ultrasonography in one case revealed optic disc bulge in the affected eye with tight traction by local detached vitreous posterior limiting membrane at the edge. The overall visual prognosis was excellent and the bleeding could be completely absorbed.

Conclusion: IHAPSH tends to appear in young women with myopia. The mechanism may be attributed to an incomplete posterior vitreous detachment (PVD), followed by a tightly vitreous-papilla adhesion and concentrated traction to the superonasal part of the tilted small optic disc.

Keywords: IHAPSH, incomplete posterior vitreous detachment, elevated optic papilla, B-ultrasonography

\section{Introduction}

Intrapapillary hemorrhage with adjacent peripapillary subretinal hemorrhage (IHAPSH) is a rare clinical syndrome, and patients with it often have sudden discomfort with symptoms such as shadow floating, scotoma and non-specific vision loss. IHAPSH most commonly occurs in Asian patients, especially in eyes with high myopia. ${ }^{1}$ Kokame et al. report that the patients are often female, ranging from teenagers to elders, with an average age of 47 years. ${ }^{2}$ However, some 
investigators suggests a pattern of younger patients. ${ }^{3}$ Though the cases of IHAPSH have been reported only very rarely, some common features of IHAPSH have been concluded as follows: ${ }^{2-5}$ (1) monocular sudden onset; (2) often occurs in myopia with tilted optic disc; (3) multiple types of bleeding can be mixed; (4) good visual acuity; (5) benign prognosis and seldom recurs. The hemorrhage in IHAPSH, which can extend to the papillary subretinal space and often into the vitreous body, is most commonly around the nasal papilla or accompanied by flame hemorrhage on the surface of optic papilla. ${ }^{2}$ As the bleeding is absorbed by itself, patients with IHAPSH has a good prognosis and do not need special treatment.

At present, the pathogenesis of IHAPSH is still unclear. Some scholars believe that incomplete posterior vitreous detachment (PVD) is the cause of bleeding, ${ }^{3}$ but the relevant clinical evidence is insufficient. In this case, we have first discovered direct evidence of optic disc traction caused by disformed optic disc and incomplete vitreous detachment in patients with IHAPSH through multimodal imaging, especially on OCT, and have speculated the pathogenesis of IHAPSH.

\section{Patients and Methods}

This was a single centre, retrospective observational study including three patients with a diagnosis of IHAPSH showing unique multimodal imaging findings that appear to reveal the possible pathogenesis of the rare disease. The three patients were screened at Department of Ophthalmology, Tongji Hospital of Huazhong University of Science and Technology (HUST), Wuhan, China, from January 2019 through November 2020. The details and images were published with the permission of the elder patient and of the legal guardians of the two young patients, which not require the approval of the institution. Written and informed consent were obtained in accordance with the Declaration of Helsinki.

Patient records were retrospectively reviewed, and data extracted for this report. All patients underwent comprehensive ophthalmic examination along with multimodal imaging that included fundus photography (Topcon 50 IX-DX, Topcon Medical Systems, Tokyo, Japan; Eidon AF, Centervue, Fremont, California, USA; Optos California, Optos, Marlborough, Massachusetts, USA); fluorescein angiography (FA) and indocyanine green angiography (ICGA) (Heidelberg Engineering, Heidelberg, Germany); spectral-domain OCT (Heidelberg
Spectralis HRA+OCT; Heidelberg Engineering, Heidelberg, Germany); and ophthalmic ultrasound (Eye Prime, Ellex, Minneapolis, USA). A comprehensive analysis and description of each patient's imaging data was performed (Figures 1-5).

\section{Results}

In our study, three eyes of three patients were included. The mean age of the patients was 24.6 years (range 15-43 years), with two females (67\%) and one male (33\%). The similar demographic and multimodal imaging characteristics are summarized in Table 1. All of them were myopia and a complaint of sudden shadow in front of the involved eyes, but no significant decline in vision. Systematic review showed that the patients did not experience any Valsalva manoeuvre and had no systemic diseases, no trauma or other medication history. The intraocular pressure and the movement of involved eyes were within normal limits. The anterior segments were normal and no definite relative afferent pupillary defect were detected. The multimodal imaging characteristics and some novel findings of patients with IHAPSH are described below.

In all three cases, the fundus photography revealed all the patients had binocular tilted and small optic discs. The involved eyes had similar fundus photography appearance which was characterized by elevated nasal optic disc, intrapapillary, nasal peripapillary, nasal subretinal, as well as mild vitreous hemorrhage (Figures 1A, 3A and 5A). In addition, in cases 1 and 2, the crescent blood strips (Figures 1A and 3A, yellow arrows) were detected in the posterior pole, which was a typical sign of incomplete PVD. Contrary to the obvious optic disc lesions, visual field examination only showed mild enlargement of physiological blind spot (Figures $1 \mathrm{~B}$ and $3 \mathrm{~B}$ ). FA and ICGA further demonstrated the hypofluorescence caused by a fluorescence masking effect from various types of hemorrhage. No dye leakage or neovascularization of the optic disc could be found on any of the involved eyes (Figures 1C, 3C and 5C).

OCT showed all patients had unique optic disc structure in both eyes (Figures 1D, 4E and 5B). It was clear on three-dimensional reconstruction that all the optic disc inclined with nasal protrusion (Figure 4C). In the involved eyes, the nasal side of peripapillary area was extremely deformed, accompanied with subretinal bleeding and nonhemorrhagic detachment of adjacent retina (Figures 1D, $4 \mathrm{E}$ and $5 \mathrm{~B}$, red arrows). In addition, localized vitreoretinal separation with residual attachment to the nasal margin of 

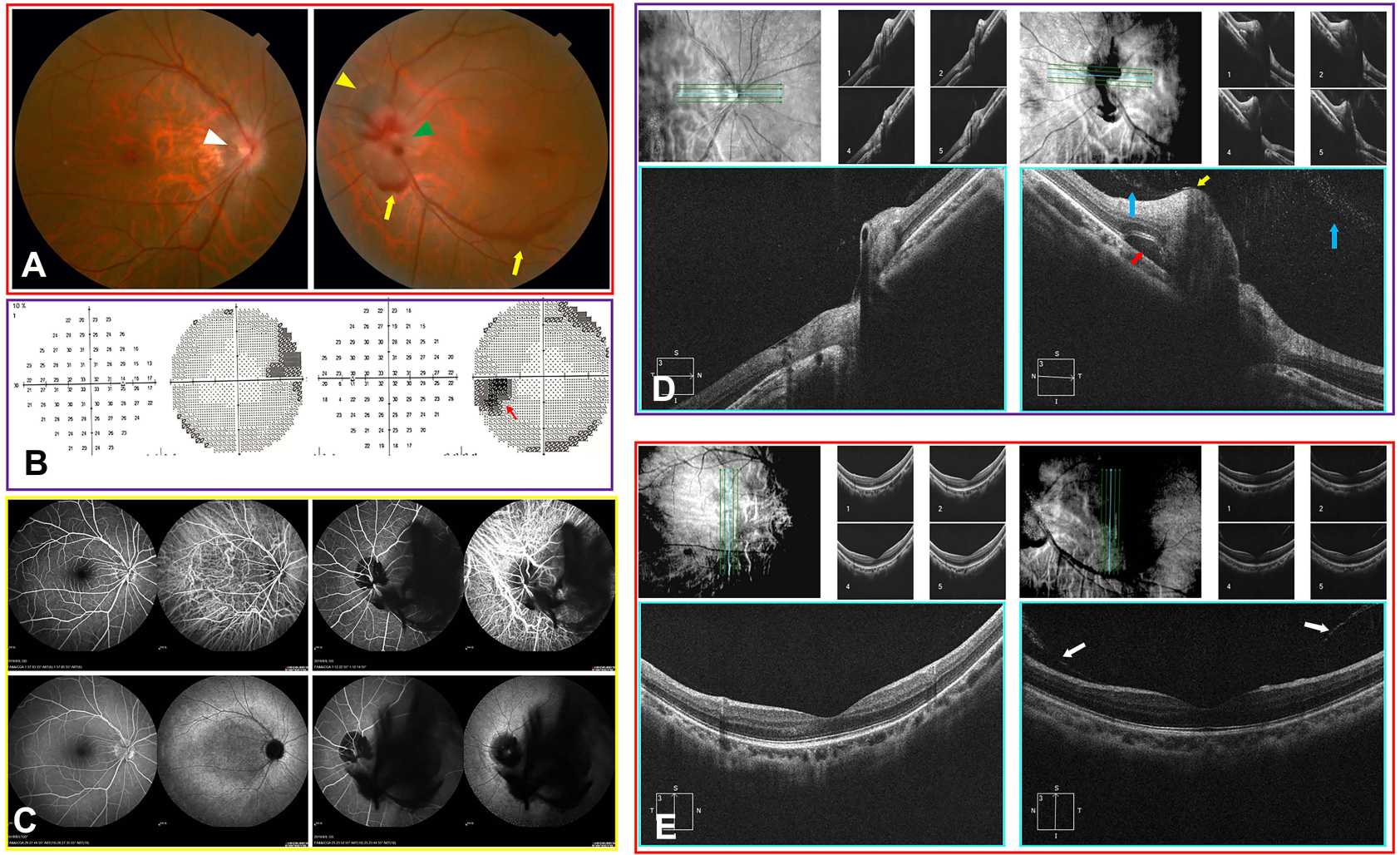

Figure I Multimodal imaging of Case I diagnosed as IHAPSH. (A) Small and tilted optic disc on her right eye (white triangle). Blurred boundary of optic disc, intrapapillary, peripapillary, and mild vitreous hemorrhage were observed in her left eye (yellow and green triangles). Two crescent blood strips were detected in the posterior pole (yellow arrows). (B) Slightly enlarged physiological scotoma on involved eye (red arrow). (C) Fluorescence masking effect on FA and ICGA without any leakage or neovascularization. (D) Optic disc elevation with hemorrhage, widening of subretinal space (red arrow), and localized vitreoretinal separation (blue arrows) with residual attachment to the superior nasal margin of the optic disc in her left eye (yellow arrow) performed by OCT. (E) Posterior vitreous membrane detachment confirmed by OCT (white arrows).

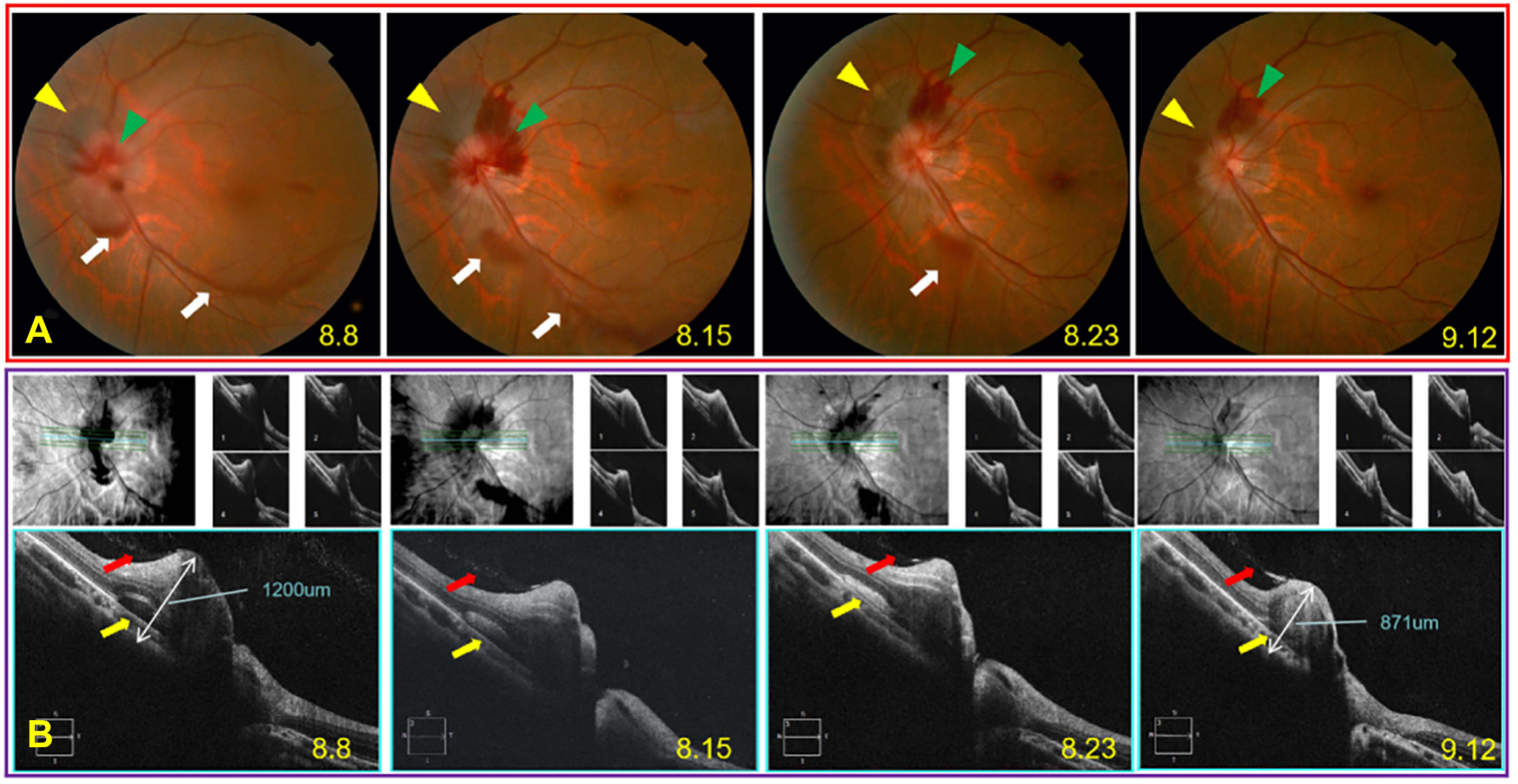

Figure 2 Follow-up of Case I for 5 weeks without any treatment. (A) Significantly subsided hemorrhage after the transient bleeding increases. (B) Persistent posterior vitreous body detachment sparing the nasal margin of the optic disc (red arrow), reduced height of the elevated optic disc (white double arrow), and the gradually disappearing subretinal hemorrhage (yellow arrows). 

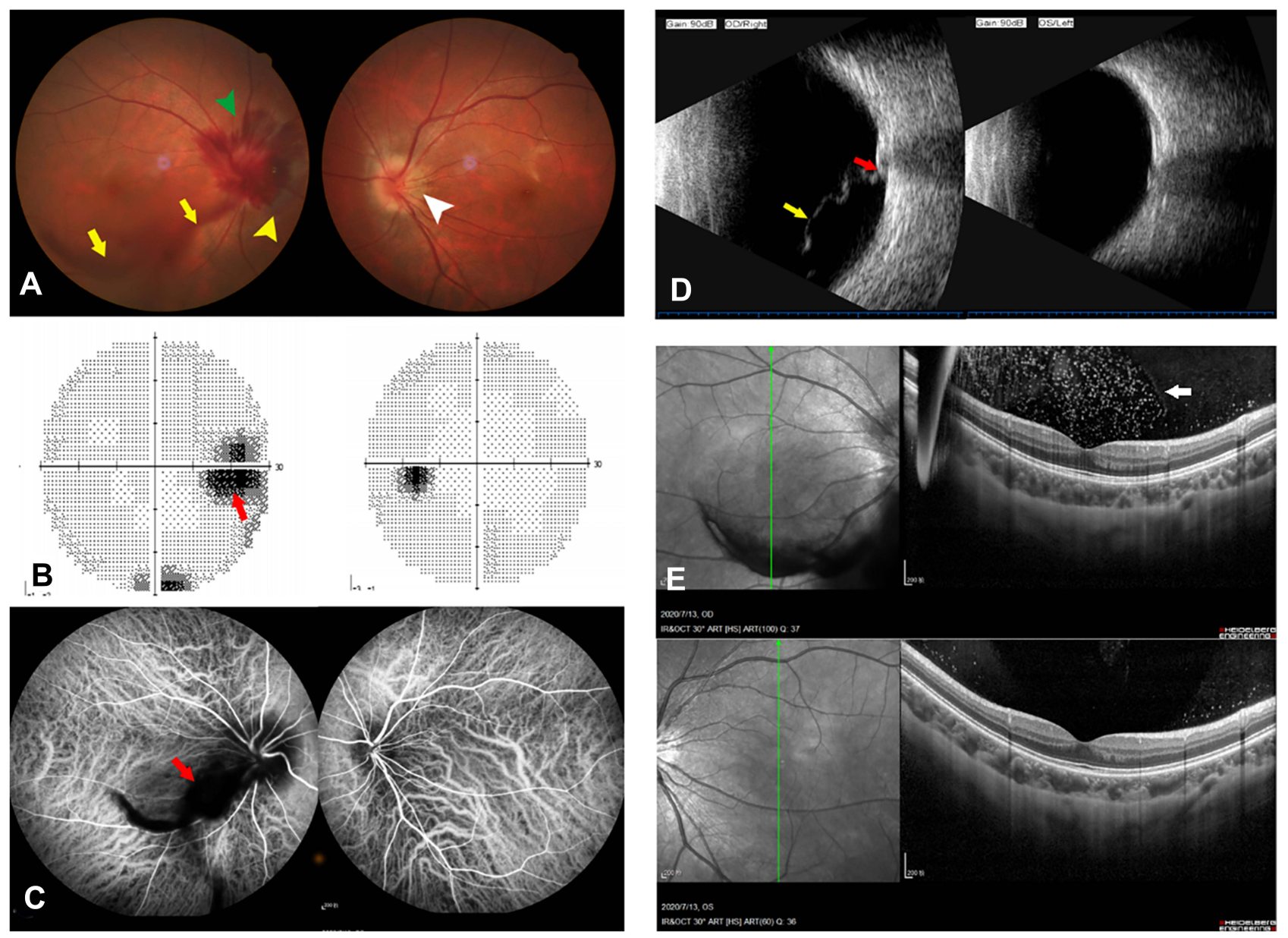

Figure 3 Multimodal imaging of Case 2 diagnosed as IHAPSH. (A) Hemorrhage in intrapapillary (green triangle), peripapillary subretinal (yellow triangle), incomplete posterior detachment and hemorrhage of vitreous body (yellow arrow) in her right eye, and a small tilted optic disc in the left eye (white triangle). (B) Enlarged physiological scotoma in the affected eye (red arrow). (C) Fluorescence blockage due to peripapillary subretinal hemorrhage (red arrow) on ICGA. (D) Incomplete posterior detachment of vitreous body adhered to the bulged optic disc in the right eye confirmed by B-ultrasonography (yellow and red arrow). (E) Posterior vitreous membrane detachment confirmed by OCT (white arrow).

the optic disc were identified in four eyes by OCT (Figures $1 \mathrm{D}$, blue arrows, $2 \mathrm{~B}$, red arrows, $4 \mathrm{E}$ and $5 \mathrm{~B}$, white arrows). The macular OCT of case 1 and case 3 revealed that the band of the posterior vitreous membrane detached from the retina in the involved eyes, while in the contralateral eyes no obvious vitreous detachment was detected (Figures 1E and 3E, white arrows). Similarly, B-ultrasonography in two involved eyes showed incomplete posterior detachment of vitreous body adhered to the bulged optic disc in the involved eyes (Figures 3D, 4D, yellow arrow and 5D, yellow and red arrows).

All patients had a good prognosis without any special interventions. The visual symptoms in all cases relieved in 2 weeks which may be due to the absorption of vitreous hemorrhage. Regardless of the location, the hemorrhage in all cases faded within two months (Figures $2 \mathrm{~A}$ and $4 \mathrm{~A}$ ), accompanied by improvement of the visual field examination (Figure 4B). OCT further demonstrated that the nasal optic disc protrusion of the affected eyes was significantly improved compared with at the onset of the disease (1200 um vs 871 um) (Figure 2B).

\section{Discussion}

The mechanism of IHAPSH is controversial, while several hypotheses have been mentioned in the literature: (1) PVD resulting in traction of optic disc associated hemorrhage. ${ }^{3,6}$ (2) The branches of short posterior ciliary artery passing through the crowded optic disc are stretched and twisted, then the local circulation is blocked, which results in bleeding. ${ }^{5}$ (3) Other stimulating factors: such as Valsalva manoeuvre. $^{2}$ Among these hypotheses, optic disc traction from the incomplete vitreous detachment is the most supported theory by several literature. Foos's study shows that PVD occurs earlier in young patients with high myopia, 

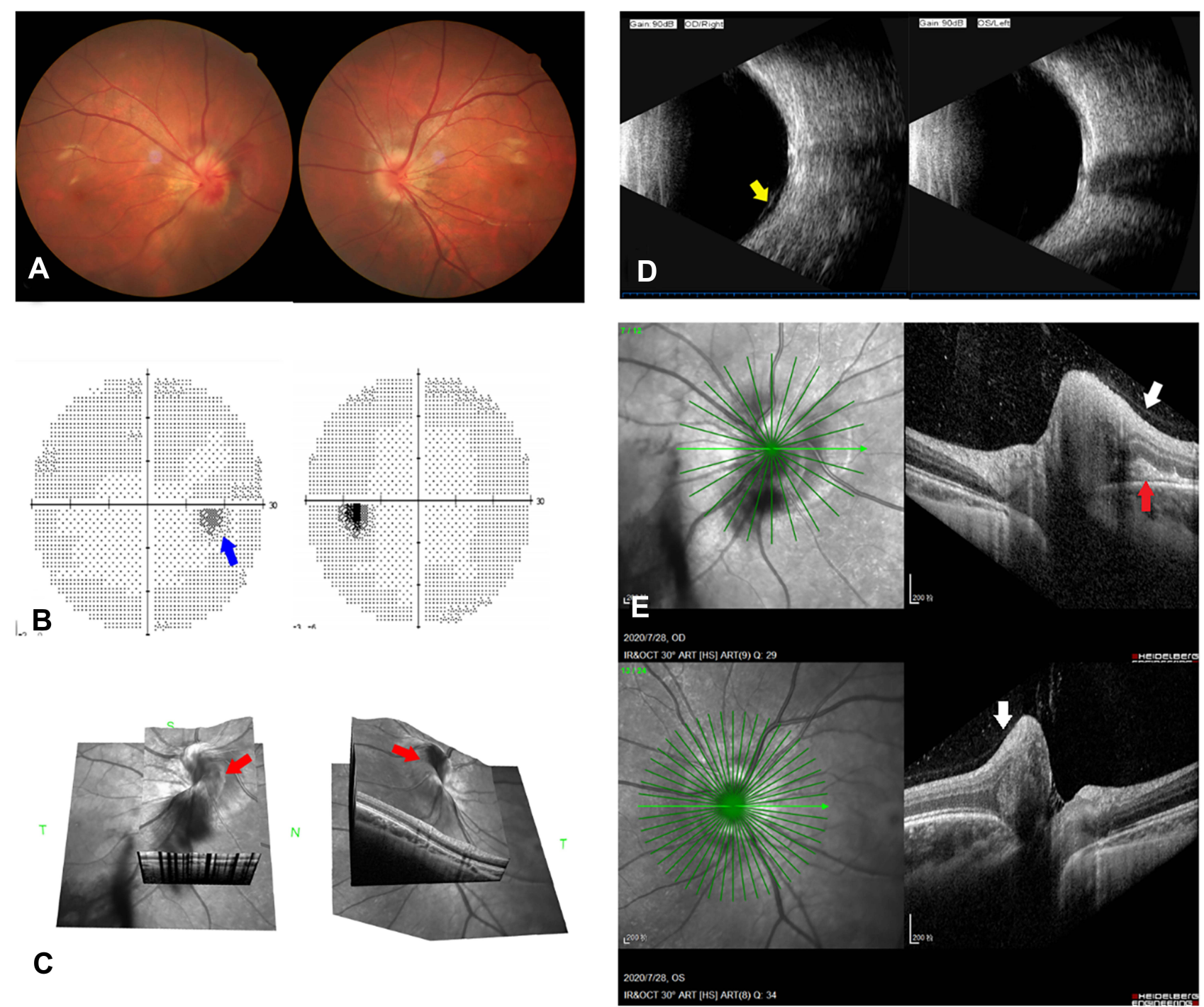

Figure 4 Follow-up of Case 2 for 2 weeks without any treatment. (A) Partially resolved hemorrhage. (B) Normalized visual field examination (blue arrow). (C) Temporal inclined optic disc with nasal protrusion revealed by three-dimensional OCT reconstruction (red arrows). (D) Continuous posterior detachment of vitreous body and adhesion to nasal side of optic discovered by B-ultrasonography (yellow arrow). (E) Local PVD with tight adhesion to the raised nasal optic disc on OCT (white arrows), subretinal bleeding (red arrow).

but the vitreous body often adheres to capillaries and optic disc, resulting in incomplete posterior detachment. ${ }^{7}$ Katz and Hoyt reported eight young patients with IHAPSH among which the B-ultrasonography revealed that the vitreous body was partially attached to the optic disc. ${ }^{3}$ They speculated that incomplete PVD was the cause of hemorrhage according to the glial marks on the optic disc. However, more clinical evidence needs to support this hypothesis.

In our cases, some important findings were detected by multimodal imaging examination: (1) all the optic discs were relatively small and inclined with nasal protrusion; (2) incomplete PVD signs existed in all cases. In two cases, the fundus color photographs showed crescent blood strips in the posterior pole, which are typical signs of incomplete PVD. OCT can intuitively observe the band caused by PVD, which was consistent with the area of PVD on the color photograph; (3) both optic disc OCT and B-ultrasonography revealed that the partly detached vitreous posterior limiting membrane was still tightly attached to the nasal edge of the optic disc. Based on the above observations, we speculate that IHAPSH is caused by the traction of the deformed optic disc by incomplete PVD. When incomplete PVD occurs except for the optic disc area, the traction will concentrate to the optic disc (Figure 6).

Myopia is a risk factor for early onset of PVD, and PVD occurs earlier in highly myopic than in normal-sighted people. ${ }^{8,9}$ The mechanism may be attributed to vitreous 

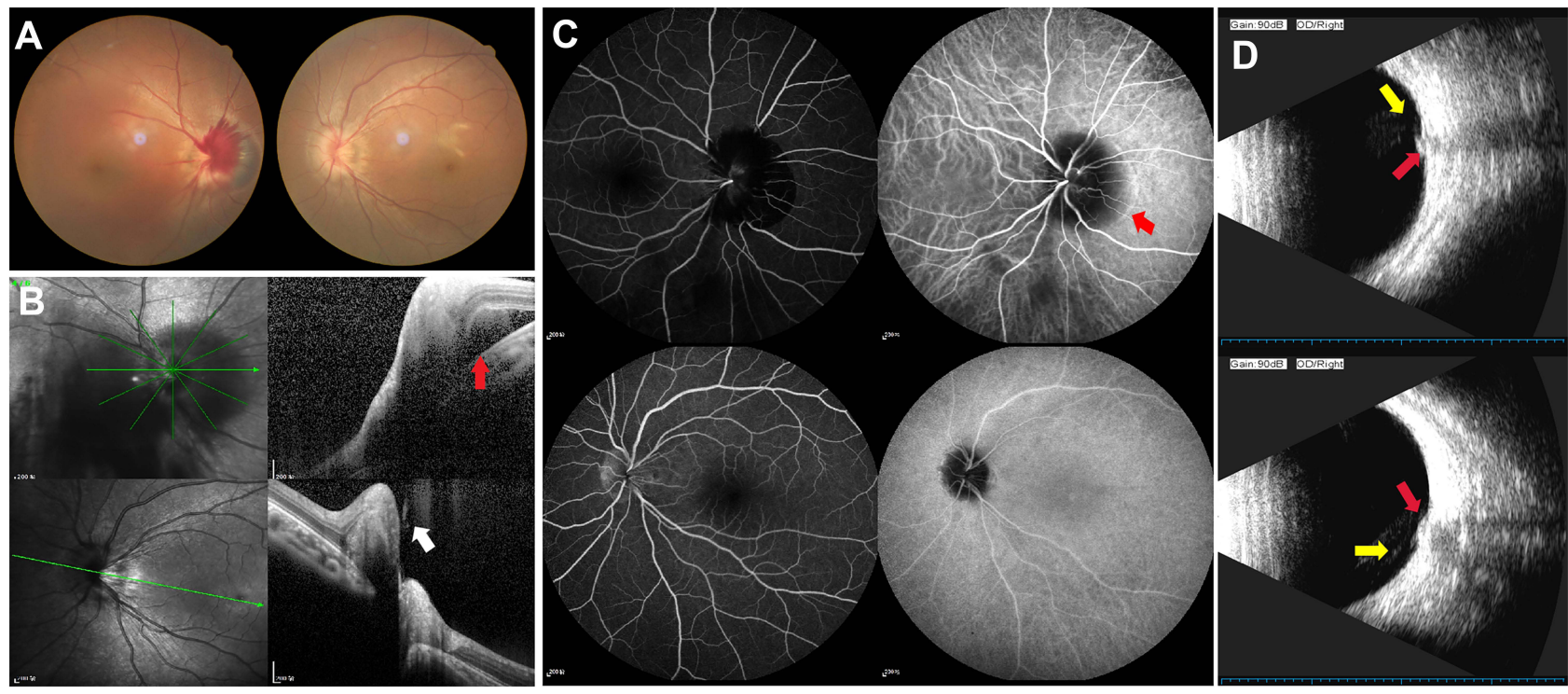

Figure 5 Multimodal imaging of Case 3 diagnosed as IHAPSH. (A) Hemorrhage in intrapapillary, peripapillary subretinal in his right eye, and a small tilted optic disc in the left eye. (B) Nasal optic disc elevation with hemorrhage, widening of subretinal space performed by OCT (red arrow); local posterior vitreous attached to the raised nasal optic disc on the contralateral eye (white arrow). (C) Fluorescence blockage due to peripapillary subretinal hemorrhage (red arrow) on ICGA. (D) Incomplete posterior detachment of vitreous body adhered to the bulged optic disc in the right eye confirmed by B-ultrasonography (yellow and red arrow).

liquefaction. Berman and Michaelson found that the concentration of protein, collagen, and hyaluronic acid in the myopic vitreous was reduced compared with a control group. ${ }^{10}$ Meskauskas also proposed a mechanical explanation for the increased risk of PVD in myopia: after analysing the mathematical model of emmetropia and myopia, they found that the vitreous body and retina continuously experience higher shear stresses during eye rotations than the normal eye due to the non-spherical shape of the vitreous chamber in the myopic eye. ${ }^{11}$ The age of myopia complicated with PVD was more common in patients over the age of 20 years old, ${ }^{12}$ while in our report, there were two cases of adolescents. Although this is rare, sporadic cases of teenagers with PVD have been seen in some studies. In Katz's report about IHAPSH, there were two cases of incomplete PVD in women with myopia younger than 15 years old. ${ }^{3}$ The study on the prevalence of subsequent retinal tears in patients with PVD also include a 15 -year-old teenager. ${ }^{13}$

Furthermore, the adhesion between vitreous and optic disc blood vessels in young patients is usually tighter than that in older people. ${ }^{14}$ Thus, the concentrated traction as well as the tightly vitreous-papilla adhesion together cause the deformation and elevation of the optic disc and even the rupture of small blood vessels around the optic disc, resulting in various types of peripapillary hemorrhage. In addition, the myopic patients often have backward tilted optic disc with

Table I Demographic and Multimodal Imaging Characteristics of Patients with IHAPSH

\begin{tabular}{|c|c|c|c|c|c|c|c|c|c|c|c|}
\hline \multirow{2}{*}{$\begin{array}{l}\text { Patient } \\
\text { No. }\end{array}$} & \multirow[t]{2}{*}{ Age } & \multirow[t]{2}{*}{ Gender } & \multirow{2}{*}{$\begin{array}{l}\text { Systematic } \\
\text { Disorders }\end{array}$} & \multirow[t]{2}{*}{ Eye } & \multirow[t]{2}{*}{ Myopia } & \multirow[t]{2}{*}{ Floaters } & \multirow{2}{*}{$\begin{array}{l}\text { Enlarged } \\
\text { Physiological } \\
\text { Scotoma on } \\
\text { VF Test }\end{array}$} & \multirow{2}{*}{$\begin{array}{l}\text { BCVA } \\
\text { at } \\
\text { Onset }\end{array}$} & \multicolumn{3}{|c|}{ Hemorrhage Location } \\
\hline & & & & & & & & & Vitreous & $\begin{array}{l}\text { Intra- } \\
\text { Papillary }\end{array}$ & Sub-Retinal \\
\hline I & 43 & $F$ & - & L & $-8 D$ & + & + & $10 / 20$ & + & + & + \\
\hline 2 & 16 & $\mathrm{~F}$ & - & $\mathrm{R}$ & $-5 D$ & + & + & $20 / 20$ & + & + & + \\
\hline 3 & 15 & $M$ & - & $\mathrm{R}$ & $-5 D$ & + & + & $20 / 20$ & + & + & + \\
\hline
\end{tabular}

Abbreviations: IHAPSH, intrapapillary hemorrhage with adjacent peripapillary subretinal hemorrhage; VF, visual field; BCVA, best corrected visual acuity; FA, fluorescein angiography; ICGA, indocyanine green angiography; OCT, optical coherence tomography; US, ultrasonography; PVD, posterior vitreous detachment. 

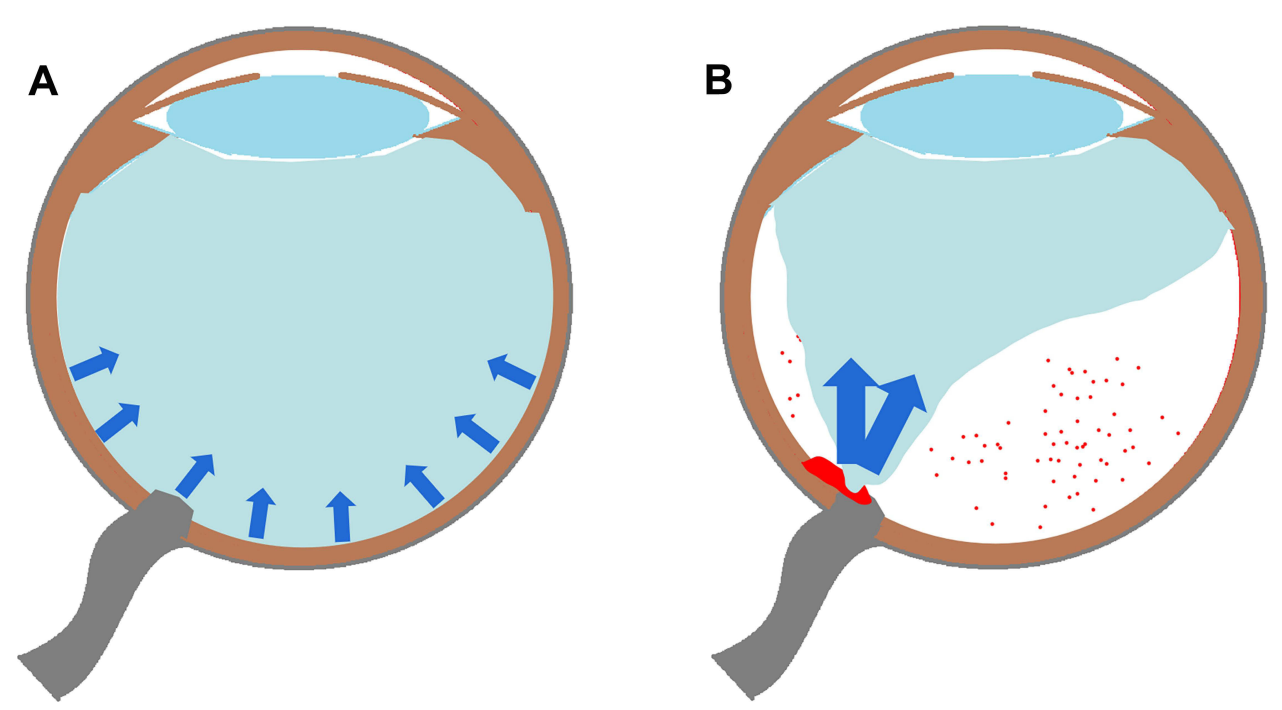

Figure 6 Illumination of vitreous traction with/without vitreous detachment. (A) Vitreous traction is uniform and dispersed (small blue arrows) when there is no vitreous detachment; (B) vitreous traction is concentrated and strengthened to the nasal optic disc (big blue arrows) with incomplete vitreous detachment sparing the optic disc, causing various types of bleeding (red spots and plaque).

relative elevation of the nasal edge, ${ }^{2,15}$ and the traction on the ridged nasal side of optic disc may be larger than the temporal side, interpreting that the hemorrhage is more common on the nasal side of IHAPSH patients.

To our knowledge, though some scholars have put forward the above hypothesis, the exact evidence were not found through B-ultrasound and OCT in many studies. ${ }^{1,2,16,17}$ Interestingly, during the follow-up of the patients, Gregg et al. ${ }^{2}$ found that 10 months after onset, the OCT of one patient showed localized vitreoretinal detachment and residual attachment to the upper edge of the optic disc. The reasons for the inconsistency of the research results may be as follows: (1) Different examination methods: B-ultrasound cannot display the vitreous-retinal relationship well due to the insufficient resolution, which is unable to observe the details of the vitreous body around the optic disc; (2) Although OCT can display the details well, it is difficult to catch the integrated sign purposefully because of the rare cases of the disease; (3) The process of PVD developed from partial to complete is difficult to capture.

When considering IHAPSH, many other diseases causing bleeding in and around the optic disc should be excluded. The major differential diagnoses are buried optic disc drusen and choroidal neovascularization, which need to be differentiated by multimodal imaging. ${ }^{18-20}$ There is only fluorescence masking effect caused by hemorrhage, indicating that IHAPSH is pseudo-papilla

\begin{tabular}{|c|c|c|c|c|c|c|c|c|c|}
\hline \multirow{2}{*}{$\begin{array}{l}\text { Small Optic } \\
\text { Disc on } \\
\text { Fundus } \\
\text { Photograph }\end{array}$} & \multicolumn{4}{|c|}{ OCT Appearance } & \multirow{2}{*}{$\begin{array}{l}\text { FA\&ICGA } \\
\text { Appearance }\end{array}$} & \multicolumn{2}{|c|}{ US Appearance } & \multirow{2}{*}{$\begin{array}{l}\text { Visual } \\
\text { Prognosis }\end{array}$} & \multirow[t]{2}{*}{ Recurrence } \\
\hline & $\begin{array}{l}\text { Elevated } \\
\text { Nasal } \\
\text { Optic } \\
\text { Disc }\end{array}$ & $\begin{array}{l}\text { Neuroretinal } \\
\text { Detachment }\end{array}$ & $\begin{array}{l}\text { Subretinal } \\
\text { Hemorrhage }\end{array}$ & $\begin{array}{l}\text { Vitreo- } \\
\text { Papillary } \\
\text { Adhesion }\end{array}$ & & $\begin{array}{l}\text { Elevated } \\
\text { Nasal } \\
\text { Optic } \\
\text { Disc }\end{array}$ & $\begin{array}{l}\text { Incompleted } \\
\text { PVD }\end{array}$ & & \\
\hline+ Bilateral & + Bilateral & + & + & + & $\begin{array}{l}\text { Blockage(+) } \\
\text { Leakage(-) }\end{array}$ & $N / A$ & N/A & Good & - \\
\hline + Bilateral & + Bilateral & + & + & + & $\begin{array}{l}\text { Blockage(+) } \\
\text { Leakage(-) }\end{array}$ & + & + & Good & - \\
\hline+ Bilateral & + Bilateral & + & + & + & $\begin{array}{l}\text { Blockage(+) } \\
\text { Leakage(-) }\end{array}$ & + & + & Good & - \\
\hline
\end{tabular}


edema without any inflammation. Although the prognosis is excellent without any special treatment, appropriate diagnosis is particularly important to avoid unnecessary mismedication and anxiety in patients.

In conclusion, we first confirmed the direct evidence of optic disc traction caused by incomplete PVD in patients with IHAPSH. Our findings support that the mechanism of IHAPSH mainly attributes to the increased traction to the optic disc and tightly vitreous-papilla adhesion caused by the incomplete PVD. Tilted small optic disc of myopia may increase this tendency of bleeding.

\section{Funding}

This study was funded by grants from the National Natural Science Foundation of P.R. China (Grant No. 81974136) and grants from the Huazhong University of science and Technology Foundation of P.R. China (Grant No. 2020kfyXGYJ068).

\section{Disclosure}

The authors report no conflicts of interest in this work.

\section{References}

1. Teng Y, Yu X, Dong L, Teng Y, Su Y. Clinical characteristics and pathogenesis of intrapapillary hemorrhage with adjacent peripapiilary subretinal hemorrhage. Chin J Ophthamol. 2012;48(2):131-136.

2. Kokame GT, Yamamoto I, Kishi S, Tamura A, Drouilhet JH. Intrapapillary hemorrhage with adjacent peripapillary subretinal hemorrhage. Ophthalmology. 2004;111(5):926-930. doi:10.1016/j. ophtha.2003.08.040

3. Katz B, Hoyt WF. Intrapapillary and peripapillary hemorrhage in young patients with incomplete PVD: signs of vitreopapillary traction. Ophthalmology. 1995;102(2):349-354. doi:10.1016/S0161-6420(95) 31018-4

4. Moon IH, Lee SC, Kim M. Intrapapillary hemorrhage with concurrent peripapillary and vitreous hemorrhage in two healthy young patients. BMC Ophthalmol. 2018;18(1):1-5. doi:10.1186/s12886-018-0833-z

5. Sibony P, Fourman S, Honkanen R, El Baba F. Asymptomatic peripapillary subretinal hemorrhage: a study of 10 cases. J Neuro
Ophthalmol. 2008;28(2):114-119. doi:10.1097/WNO.0b013e318175 $\operatorname{cd} 90$

6. Cibis GW, Watzke RC, Chua J. Retinal hemorrhages in PVD. Am J Ophthalmol. 1975;80(6):1043-1046. doi:10.1016/0002-9394(75)903 34-7

7. Foos RY. Posterior vitreous detachment. Trans Am Acad Ophthalmol Otolaryngol. 1972;76(2):480-497.

8. Yonemoto J, Noda Y, Masuhara N, Ohno S. Age of onset of posterior vitreous detachment. Curr Opin Ophthalmol. 1996;7(3):73-76. doi:10.1097/00055735-199606000-00012

9. Itakura $\mathrm{H}$, Kishi $\mathrm{S}$, Li D, Nitta K, Akiyama H. Vitreous changes in high myopia observed by swept-source optical coherence tomography. Investig Ophthalmol Vis Sci. 2014;55(3):1447-1452. doi:10.11 67/iovs.13-13496

10. Berman E, Michaelson I. The chemical composition of the human vitreous body as related to age and myopia. Exp Eye Res. 1964;3 (1):9-15. doi:10.1016/S0014-4835(64)80003-8

11. Meskauskas J, Repetto R, Siggers JH. Shape change of the vitreous chamber influences retinal detachment and reattachment processes: is mechanical stress during eye rotations a factor? Invest Ophthalmol Vis Sci. 2012;53(10):6271-6281. doi:10.1167/iovs.11-9390

12. Hayashi K, Manabe S, Hirata A, Yoshimura K. Posterior vitreous detachment in highly myopic patients. Invest Ophthalmol Vis Sci. 2020;61(4):33. doi:10.1167/iovs.61.4.33

13. Crim N, Esposito E, Monti R, et al. Myopia as a risk factor for subsequent retinal tears in the course of a symptomatic posterior vitreous detachment. BMC Ophthalmol. 2017;17(1):226. doi:10.11 86/s12886-017-0629-6

14. Sebag J. Ageing of the vitreous. Eye. 1987;1(2):254-262. doi:10.10 38/eye. 1987.45

15. Jonas JB, Ohno-Matsui K, Panda-Jonas S. Myopia: anatomic changes and consequences for its etiology. Asia Pacific J Ophthalmol. 2019;8 (5):355-359. doi:10.1097/01.APO.0000578944.25956.8b

16. Teng Y, Yu X, Teng Y, et al. Evaluation of crowded optic nerve head and small scleral canal in intrapapillary hemorrhage with adjacent peripapillary subretinal hemorrhage. Graefes Arch Clin Exp Ophthalmol. 2014;252(2):241-248. doi:10.1007/s00417-013-2459-4

17. Kokame GT. Intrapapillary, peripapillary, and vitreous hemorrhage. Ophthalmology. 1995;102(7):1003-1004. doi:10.1016/S0161-6420 (95)30923-2

18. Rubinstein K, Ali M. Retinal complications of optic disc drusen. $\mathrm{Br} J$ Ophthalmol. 1982;66(2):83-95. doi:10.1136/bjo.66.2.83

19. Lee KM, Hwang JM, Woo SJ. Hemorrhagic complications of optic nerve head Drusen on spectral domain optical coherence tomography. Retina. 2014;34(6):1142-1148. doi:10.1097/IAE.0000000000000040

20. Cheung CMG, Arnold JJ, Holz FG, et al. Myopic choroidal neovascularization: review, guidance, and consensus statement on management. Ophthalmology. 2017;124(11):1690-1711. doi:10.1016/j.ophtha. 2017.04.028
Clinical Ophthalmology

\section{Publish your work in this journal}

Clinical Ophthalmology is an international, peer-reviewed journal covering all subspecialties within ophthalmology. Key topics include: Optometry; Visual science; Pharmacology and drug therapy in eye diseases; Basic Sciences; Primary and Secondary eye care; Patient Safety and Quality of Care Improvements. This journal is indexed on PubMed
Central and CAS, and is the official journal of The Society of Clinical Ophthalmology (SCO). The manuscript management system is completely online and includes a very quick and fair peer-review system, which is all easy to use. Visit http://www.dovepress.com/ testimonials.php to read real quotes from published authors.

\section{Dovepress}

